03;15

\title{
Исследование ударных волн в электрохимическом микроактюаторе
}

\author{
(c) A.В. Постников
}

Ярославский фрилиал Физико-технологического института РАН, Ярославль, Россия

E-mail: mems@yf-ftian.ru

Поступило в Редакцию 25 июля 2018 г.

Исследован взрывной режим работы электрохимического микроактюатора. В этом режиме происходит взрыв микропузырьков смеси водорода и кислорода, образующихся в процессе электрохимического разложения воды высокочастотными импульсами переменной полярности, в рабочей камере электрохимического микроактюатора. Показано, что ударная волна возникает не вследствие взрыва микропузырька, а в результате кавитации взрывной полости. На основе экспериментального определения зависимости скорости ударной волны от расстояния до центра взрыва найдено давление в ударной волне. Определена динамика схлопывания микропузырька на основе скоростной теневой фотографии.

DOI: 10.21883/PJTF.2018.23.47017.17475

Мембранный актюатор является широко распространенным устройством микрофлюидики [1-3]. Это ключевая часть микронасосов, клапанов и других устройств, используемых в био- и химическом анализе, системах дозирования лекарств, биологического секвенирования. К основным параметрам таких устройств относятся их надежность, потребляемая мощность, простота и стоимость изготовления, а также биосовместимость, скорость работы и точность дозировки. Электрохимический актюатор очень привлекателен, поскольку имеет простую конструкцию, развивает значительные усилия. Действие актюатора основано на генерации газа в электрохимическом процессе с последующим его удалением из систем. Главный недосток такого актюатора - длительный рабочий цикл по причине медленной рекомбинации газа в рабочем объеме. В [4] был представлен электрохимический микроактюатор, использующий для разложения воды и генерации газов импульсы переменной полярности высокой частоты [5]. Принцип работы прибора 
основан на том, что в рабочем объеме производится газовая смеь кислорода и водорода. Эти газа содержатся в нанопузырьках, которые при достижении определенного уровня перенасыщения могут сливаться в микропузырьки, содержащие стехиометрическую смесь газов. В таких микропузырьках происходит спонтанная реакция кислорода и водорода. Причины этой реакции выяснены не до конца, однако ясно, что реакция идет вследствие присутствия в объеме нанокапель воды. Реакция носит взрывной характер и вызывает значительный подъем давления в камере актюатора. Рабочий цикл актюатора в таком режиме составляет единицы миллисекунд. Это на несколько порядков меньше, чем в известных к настоящему времени конструкциях, используемых в микрофлюидике.

В данном исследовании рассмотрен взрывной режим работы актюатора. Непрозрачная мембрана, закрывающая рабочий объем актюатора, мешает проведению измерений, поэтому она была удалена. Подложка с прибором помещелась в кювету с одномолярным раствором сульфата натрия в вертикальном положении. На уровне электродов через кювету проходит несфокусированный луч гелий-неонового лазера с длиной волны $632 \mathrm{~nm}$. Диаметр пучка лазера составляет $0.55 \mathrm{~nm}$. Луч лазера отклоняется в горизонтальной плоскости, если в среде возинкает градиент показателя преломления. Угловое отклонение луча с помощью линзы преобразуется в линейное смещение в плоскости фотоприемника. Двух сегментный фотоприемник имеет полосу пропускания $3 \mathrm{MHz}$. Луч лазера в исходном положении засвечивает в равной степени оба сегмента фотоприемника. Сигналы с обоих сегментов регистрируются запоминающим осциллографом PicoScope 5000. Полоса частот осциллографа $100 \mathrm{MHz}$. Кювета с электролитом и прибором размещается на микропозиционере. Микропозиционер дает возможность изменять расстояние от прибора до лазерного луча с точностью $10 \mu \mathrm{m}$ в диапазоне $50 \mathrm{~mm}$.

Рабочий цикл актюатора состоит из следующих стадий, обозначенных цифрами на рис. 1: приозводство смеси газов до достижения определенной величины перенасыщения - инкубация (1), рост микропузырька (2), стационарная фаза (3) и, наконец, схлопывание микропузырька (4). Эти характерные стадии различаются поведением тока, протекающего через электролит. На рис. 1 верхняя трасса представляет импульсы тока. Падение тока на участке 2 продолжается $60-70 \mu \mathrm{s}$. За это время пузырь со смесью газов достигает размеров электродов, и ток почти прекращается. На указанной стадии не происходит формирования

Письма в ЖТФ, 2018, том 44, вып. 23 


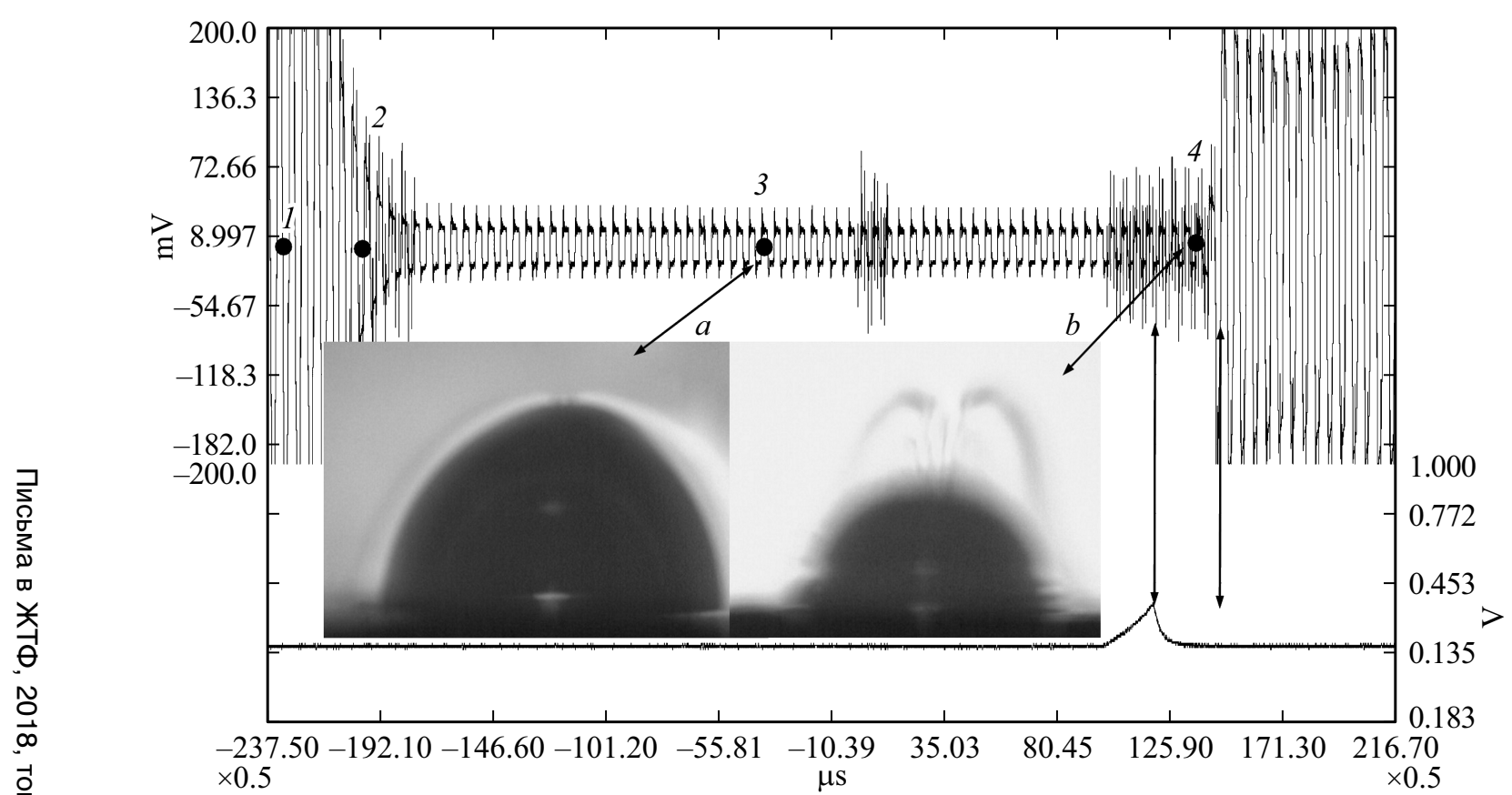

Рис. 1. Осциллограммы тока, протекающего через электролит, и синхроимпульса скоростной камеры. Цифры $1-4$ поясняются в тексте. На вставке $a-$ теневая фотография пузырька в стационарной фазе, на вставке $b-$ теневая фотография пузырька, соответствующая синхроимпульсу. 
ударной волны по следующей причине. Во время периода инкубации в жидкости образуется облако нанопузырьков над электродами [6]. Это область с плотностью, меньшей, чем у воды, поэтому она играет роль демпфера и не дает возможности сформироваться ударной волне. Стационарная фаза продолжается $200-300 \mu \mathrm{s}$ (область 3 на рис. 1). Этому моменту соответствует теневая фотография пузырька на вставке $a$ к рис. 1. Вокруг пузырька видно светлое гало - это облако нанопузырьков. Показатель преломления в облаке нанопузырьков меньше, чем в окружающем электролите. Высота пузырька составляет $1.5 \mathrm{~mm}$. Схлопывание пузырька продолжается примерно $50 \mu \mathrm{s}$ (участок 4 на рис. 1). Время схлопывания определено с помощью скоростной фотографии. Нижняя трасса на рис. 1 показывает положение синхроимпульса, во время которого камера собирает данные, время экспозиции $20 \mu \mathrm{s}$. Теневая фотография на вставке $b$ к рис. 1 соответствует моменту синхроимпульса камеры. Время от окончания синхроимпульса до полного восстановления тока это и есть время схлопывания пузырька (обозначено вертикальными стрелками на рис. 1). При схлопывании пузырька образуется ударная волна, которая регистрируется фотоприемником как градиентное изменение оптической плотности электролита. На небольшом расстоянии от электродов в месте формирования волны ее скорость превышает скорость звука в среде [7]. Для измерения скорости распространения ударной волны луч лазера перед прохождением через кювету с помощь двулучепреломляющей пластинки расщепляется в горизонтальной плоскости на два луча равной интенсивности. Таким образом, фронт ударной волны пересекает сначала один пучок, затем второй. Расстояние между центрами лазерных пучков составляло $1.5 \mathrm{~mm}$. Каждый пучок из пары попадал на разные сегменты фотоприемника. Измеряя время между максимумами откликов разных сегментов фотоприемника, можно по известному расстоянию между лучами вычислить скорость ударной волны. На рис. 2 представлены сигналы сегментов фотоприемника при прохождении через лучи ударной волны. На вставке к рис. 2 приведены панорама сигналов с фотоприемников и изменение тока через электролит при формировании и взрыве микропузырька. Из рис. 2 видно, что окончание сигнала сегмента 1 соответствует началу отклика сегмента 2. Это означает, что расстояние между пучками лазера равно протяженности ударной волны. Изменяя расстояние пары пучков до подложки с электродами, можно измерить изменение скорости ударной волны. Из-за относительно большого расстояния

Письма в ЖТФ, 2018, том 44, вып. 23 


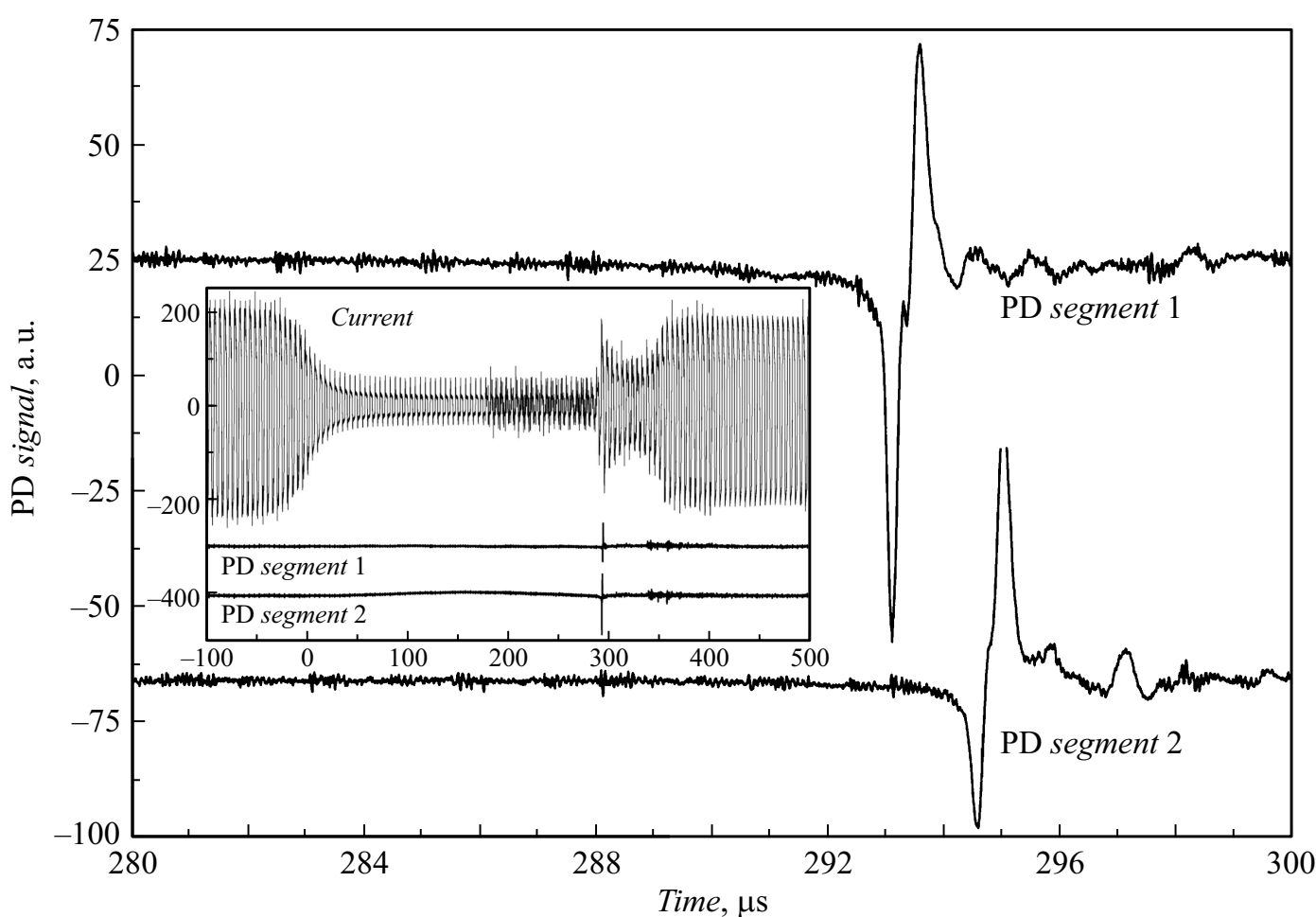

Рис. 2. Отклики сегментов фотоприемника при пересечении лазерного пучка ударной волной. На вставке панорамная осциллограмма с током через электролит. 


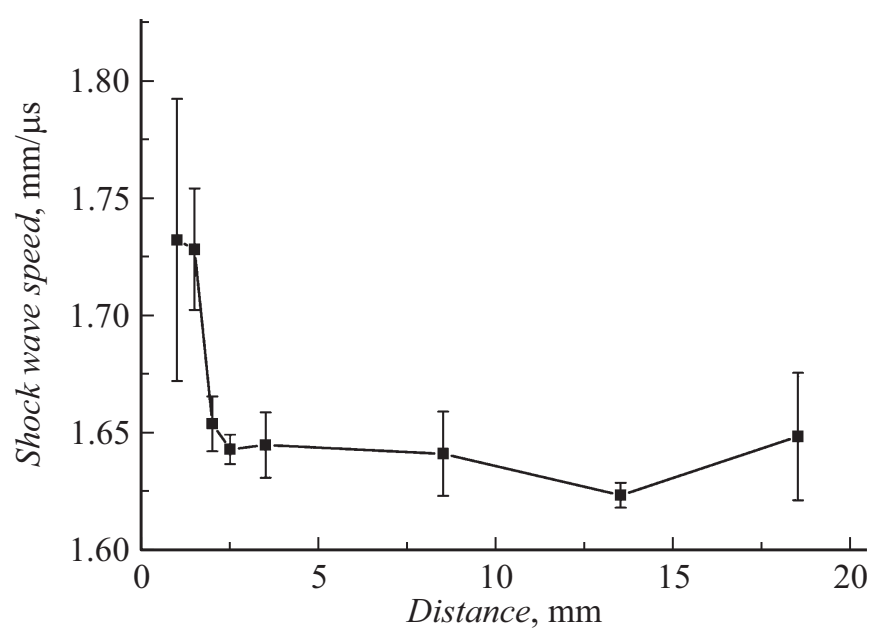

Рис. 3. Изменение скорости ударной волны в зависимости от пройденного расстояния.

между пучками такие измерения будут давать заниженный результат, поскольку замедление происходит на масштабе $5-10 \mathrm{~mm}$. Зависимость скорости распространения ударной волны от расстояния до электродов представлена на рис. 3. На расстоянии более $3 \mathrm{~mm}$ от электродов до середины расстояния между пучками скорость распространения равна скорости звука в электролите (по данным, приведенным в [8]). Энергия взрывов микропузырьков не является постоянной, а имеет значительную дисперсию по величине. При приближении пучков к электродам на расстояние меньше миллиметра это выражается в большом разбросе экспериментальных данных. Согласно модели Гилмора [9] и уравнению состояния Тейта, соотношение между давлением и скоростью ударной волны записывается следующим образом:

$$
p_{s}=\left(p_{a}+B\right)\left(\frac{2 n u_{s}^{2}}{(n+1) c_{0}^{2}}-\frac{n-1}{n+1}\right)-B
$$

где $p_{s}$ - давление в ударной волне, $p_{a}$ - равновесное давление в жидкости, $c_{0}-$ скорость звука в электролите $(1.64 \mathrm{~mm} / \mu \mathrm{s}), u_{s}-$ скорость ударной волны, показатель $n$ равен 7, $B$ - константа, равная

Письма в ЖТФ, 2018, том 44, вып. 23 
$314 \mathrm{MPa}$. Исходя из данных, представленных на рис. 3, давление на фронте ударной волны составляет $p_{s}=74 \mathrm{MPa}$.

В результате проведенного исследования показано, что ударная волна формируется при схлопывании пузырька, образованного при взрыве микропузырька со смесью кислорода и водорода. Дана количественная оценка протяженности самой ударной волны. На основе модели Гилмора и измерений скорости ударной волны в зависимости от пройденного расстояния вычислено давление на фронте ударной волны. Таким образом, полученные результаты способствуют детальному пониманию процессов при работе электрохимического микроактюатора во взрывном режиме.

Работа выполнена в рамках государственного задания ФАНО России с использованием оборудования Центра коллективного пользования диагностики микро- и наноструктур.

\section{Список литературы}

[1] Yi Y., Buttner U., Carreno A.A.A., Conchouso D., Foulds I.G. // J. Micromech. Microeng. 2015. V. 25. P. 105011.

[2] Lee D.E., Soper S., Wang W. // Microsyst. Technol. 2008. V 14. P. 1751-1756.

[3] Werber A., Zappe H. // J. Microelectromech. Syst. 2008. V. 17. P. 1218-1227.

[4] Uvarov I.V., Lokhanin M.V., Postnikov A.V., Melenev A.E., Svetovoy V.B. // Sensors Actuators B: Chemical. 2018. V. 260. P. 12-20. DOI: $10.1016 /$ j.snb.2017.12.159

[5] Svetovoy V.B., Remco G.P., Sanders R.G.P., Elwenspoek M.C. // J. Phys.: Condens. Matter. 2013. V. 25. P. 184002. DOI: 10.1088/0953-8984/25/18/184002.

[6] Postnikov A.V., Uvarov I.V., Lokhanin M.V., Svetovoy V.B. // PLoS ONE. 2017. V. 12. P. e0181727. DOI: 10.1371/journal.pone.0181727

[7] Brennen C.E. Cavitation and bubble dynamics. N.Y-Oxford: Oxford University Press, 1995. P. 282.

[8] Chen C.T., Chen L.S., Millero F.J. // J. Acoust. Soc. Am. 1978. V. 63. P. 17951800.

[9] Vogel A., Busch S. // J. Acoust. Soc. Am. 1996. V. 100. P. 148-165. 